\title{
Cooperation and Competition Among Enterprises and Their Advantages and Disadvantages
}

\author{
Lin Jun*
}

\author{
Xiamen No.3 Middle School \\ *Corresponding author.1157329438@qq.com
}

\begin{abstract}
My thesis is talking about economy, and it discusses the relationship between cooperation and competition between enterprises and their respective advantages and disadvantages. The survey methods used are descriptive literature and research method. It also involves the concepts of competition and cooperation. I selected some important content from Baidu Library. The conclusion drawn from the research is that there is a relationship between cooperation and competition among enterprises, and they have advantages and disadvantages respectively.
\end{abstract}

Keywords: Business cooperation, Business competition, Trust, ChunDou, Shuanghui

\section{INTRODUCTION}

Nowadays, we can see the scene that the cooperation and competition are very common to see in the relationship of companies, such as Shenyin wanguo securities and Hong yuan securities merger and the competition of Jindong and Taobao. So, this is an interesting phenomenon- why this kind of relationship happens between the individual company produce? And from this interesting phenomenon, other problems are also put forward: what is the meaning of cooperation and competitions? Cooperation and competition will let them benefit from it? What is the disadvantage of cooperation and competition? In this paper, I want to talk about and solve these problems. Then, I will summarize the advantages and disadvantages of cooperation and competition. In my opinion, I think that competition and cooperation are conducive to the company in the end. For this reason, we can use the traditional game theory to explain: everyone is from his own interests and no one will be willing to do things against his own. Relationship in the future, the company will have more cooperation and competition, because there is more business. If we have a very good understanding of the advantages and disadvantages of cooperation and competition, we can in the face of competition and cooperation of better choices, and better use of relations of cooperation and competition to obtain benefits.

\section{THE CONCEPT OF COMPETITIONS AND AN EXAMPLE OF THE COMPETITION}

Between competition is an individual or group trying to trump or overwhelm the other side of the psychological needs and activities.

"The traditional competition of companies is using all of the way to defeat the enemy and keep them away from the market. The success of the one company is based on the defeat and disappearing of the other company. There is no me and you are at loggerheads is the prevailing market rules of competitions. [1]" In the enterprise, companies are competing with each other, and at the expense of the interests of the other companies to make their own interests to maximize. Let's imagine a simple scenario to help us to understand this concept: in a closed confined space without any food for two days. Then suddenly into the confined space a only just big enough for three people to eat pizza. This a pizza to each of them is a huge temptation, because they did not eat for two days, so they are very hungry. In this case, the six men will try to grab more pizza to fill their stomachs. They are each single individual competition. Competition in order to maximize their own interests which means they comtete for enough $\mathrm{t}$ pizza to eat. And group competition is the six people into several groups, in order to get for team's best interests and competition with other groups. As the six men were 
divided into the two groups a and $b$, one team has three people. A group of three people to get to the three people's share of the pizza will compete with b group of three people. Is also at the expense of the interests of the opposing team to get to his team's best interests.

\subsection{An Example}

ChunDou and Shuanghui both domestic famous sausage merchants. They compete with each other, in order to seize more market sausage. ChunDou and shuanghui competition lead to the success of ChunDou and the defeat of shuanghui.

Because under the pressure of competition, both sides choose different diversity strategies. And ChunDou choices a failure ChunDou sausage business in competition in the process of the choice of diversification strategy direction there is an error. ChunDou, many companies began to lose themselves, choose the wrong direction. ChunDou not only decreases their prices and weakened the quality of the sausage. ChunDou sausage flour content ratio is bigger and bigger. Finally, in ChunDou sausage appeared on the market of the so-called "stick" of the sausage products which is a sausage, flour content seriously over the standard. ChunDou of this kind of practice is to maintain item available profits before cutting down the price. Although the company of Chundou gets a lot of benefits on the item of price advantage, it has lost as a sausage maker's original core competitive ability which is the content of meat and sausage tastes. Shuanghui sausages company, by contrast, choose the correct diversification strategy. Shuanghui company uses the core strategy. Shuanghui company know their own position and development direction clearly. They develop their own business. Shuanghui in their meat products processing industry chain has a synergistic effect on sales, operation, and management. On this chain of every part are well integrated.

In addition, shuanghui company because of the continued development of its own core ability (quality) of the sausage, finally gain the praise of consumers and loyalty, and shuanghui company establishes a good image in the sausage in the market. Therefore, the competition of two companies, Shuanghui company made the final victory.

\subsection{Advantages}

The positive role is to be able to make the enterprise spirits, strenuous enterprising, promote social progress and improve labor productivity. In the competition are the shuanghui and spring. Shuanghui company is in order to obtain more sales market of the sausage. Each part of the enterprise's production chain is integrated very well. And work hard, to develop their own core ability, improve the quality of the sausage. Shuanghui under such an effort, and got great progress on the quality of the sausage. Is good for consumers, because have a better quality of the sausage appeared means they purchased food quality will be improved. Shuanghui's victory in the competition at the same time, the warning to other enterprises to develop their core competence as the basis. Successfully promoted social progress.

\subsection{Disadvantages}

Its negative effect is to discourage both sides, make limited resources to play the best benefit, causing the disunity between individuals or groups, is not conducive to the establishment and development of the interpersonal relationship. Because one party is successful, means that the other party is going to fail, for example, ChunDou failure of the company. ChunDou company lost in the competition for food production resembles the development level of food quality (), but the extreme means of profit. Therefore, ChunDou company lost the big sausage sales market and the credibility of the enterprise. The negative influence is very big to the impact of ChunDou company because it means ChunDou company will lose its competitive ability. ChunDou owned enterprises will face collapse, negative profit. In addition, after shuanghui company win the competition, so lost ChunDou this competition. In the case of lost the competition, ChunDou company began to appear lost its strategic direction. Shuanghui sausages company in order to obtain more profits, its production quality level of the sausage began to decline, the corners phenomenon. Eventually, shuanghui sausage company to decline gradually.

\section{COOPERATION}

A form of joint operations between individual and individual, group and group to achieve a common purpose, a joint effort to cooperate with each other.

Cooperation of the basic conditions for successful cooperation needs to have the basic conditions mainly include: (1) Consistent goal. Any cooperation is to have a common goal, at least in the short-term goal together. (2) The understanding of the unity and specifications. Partners to deal with the common goal, realizing method and steps, etc., have almost the same understanding; Partners in joint operations must comply with the common recognition of social norms and group norms. (3) Trust each other cooperation atmosphere. To create mutual understanding, trust each other, support each other and a good mood is the important condition of effective cooperation. (4) With 
cooperation relies for survival and development of a certain material base. "In the procession of the cooperation, companies should choose the suitable way which is based on the understanding and analyze of advantageous resources of both sides in order to get the highest improvement of ability of competition." "they should establish the concept of win-win and all win philosophy. [2] In the same way, we can use a simple example to explain what is cooperation. Everyone has seen the animal world. When I was watching the show has seen the show to discuss lion predation. They are not in the individual as the unit to prey. But in groups to hunt prey. Then show sees lions capture buffalo. There are several lioness goals is to capture the same only buffalo. They have a common goal. Some attack prey in the foot. Some throat belly and other vulnerable places. This is a unified standard and understanding. Because they are assigned the orderly prey. Otherwise capture not the possibility to succeed. To mutual trust between them. If there is no trust in each other. First, no one is willing to prey. Because the first shots of the lion could be a hit. And the lion who strikes the first attack places not Achilles heel prey. So, the first shots of the lion and cannot directly kill its prey. And then to the lion can then take advantage of the first to hit prey to the lion's injury or after, and starting with the lion's mouth away from its prey. Of course, this is very rare. Because a lion group is a male lion as a leader. They are to serve the leader. In addition, they have a good feed on the formation and sharp claws and teeth. These are their material base.

\subsection{An Example}

Wal-Mart and Procter \& gamble's cooperation "in the second half of 1927, Procter \&gamble and Wal-Mart started a new relationship. Both sides composed of finance, distribution, production and other functional departments of about 70 people dedicated team cooperation, the company with the help of advanced information technology to implement information sharing, collaborative management of the entire business activities for all-round. In 1989, Wal-Mart for P\&G's diapers products to build the JIT (just in time, timely) type automatic order delivery system, the enterprise through EDI and satellite communications, mmi (manufacture management, the inventory, manufacturers managed inventory) system, eft (electronic funds transfer, electronic funds settlement) system information such as the means to achieve the automatic continuous replenishment, electronic clearing, shorten the time of the circulation of commodities and traditional property settlement of red tape, achieve the substantive breakthrough 'relations of cooperation[3]. Under the condition of this cooperation, both performances have improved.

\subsection{Advantages}

From Wal-Mart and Procter \& gamble, both performances have improved. Wal-Mart stores in P\&G's diapers goods turnover increased by seventy percent; Procter \& gamble's diapers sales also increased by fifty percent, to $\$ 3$ billion. Procter \& gamble company in the domestic market sales of eleven percent is achieved by Wal-Mart, went up by twenty percent in the second year of the data (or twenty percent of the $\$ 15.6$ billion [4]This is the mutual cooperation to achieve win-win cooperation. Through the cooperation to maximize interests. Through the cooperation to help each other, make both sides company in their own industry sales market competition, more competitive. Wal-Mart and Procter \& gamble's cooperation is conducive to their long-term development. One party has international channel advantage and international commercial advantage, the other party have better together, the two sides will have the greater interests' [5] is helpful to realize the goal of an international operation, because cooperation is conducive to accelerate industry supply chain extension. Cooperation can make full use of domestic and international two markets, two resources.

\subsection{Disadvantages}

In the process of cooperation, easy in operation, the cost of investment and profit above the dispute and the self-interest is not necessarily the maximum [7].

Because both sides may need in order to maintain cooperative relations and make some concessions. In fact, Wal-Mart and Procter \& gamble company before this cooperation is cooperation and a competition experience. At the beginning of 1962, Wal-Mart is selected by Procter $\&$ gamble for goods suppliers. But because both sides want to reap maximum for their own interests, then produce unpleasant and conflict. In the end, both sides of the cooperation relationship. "Wal-Mart in order to achieve their low-price strategy, trying to large orders and delivery condition of inequality methods such as lower pleased, extend the payment period, even the threat of Procter \& gamble products in the corner, $P \& G$ reduce the price. But $\mathrm{P} \& \mathrm{G}$ does not compromise, still seeking to improve the sales price, and Procter $\&$ gamble products are put in place a better shelf "[6] the results reported by the media. Finally, jeopardizing the interests of P\&G's, Wal-Mart's reputation. So, in the process of cooperation, if not adjust good relations, is likely to lead to a lot of negative effects. 


\section{DISCUSSION}

These two kinds of relationship, competition and cooperation between the enterprises and other enterprises is one of the very common relationships. Enterprises and other enterprises to compete and cooperate with other enterprises because both companies want to gain more interest. Enterprise competition relations can expose your weaknesses. Enterprise competition can also have its own to find the right strategic direction. Cooperating with other companies will help you become stronger and become more competitive than other companies in the same industry. That is to say, cooperation and competition both business relationship is conducive to the development of enterprises. So, in the face of other enterprises, especially in the same industry enterprises, the competition not only presents this kind of relationship. Not necessarily want to compete with each other to a final point either you die or I die. In some necessary, can be through the cooperation to achieve win-win. Two companies complement each other shortcomings, make both parties through cooperation can become more powerful. For an example of Wal-Mart and Procter \& gamble, through cooperation, mutual support, provide something for each other. This makes them in the same industry enterprises in the market, more competitive. Have stronger competitiveness is more conducive to them to survive in the market competition in the industry.

But for those who cannot avoid competition, competition is very beneficial to both sides own instead. Because the competition can be a certain degree of exposure or products of its own core issues. Enterprise in knowing these after exposed defects through competition, can timely correction or efforts to progress, so as to raise their level. In addition, competition can help enterprises to find the right direction. These things are very important for an enterprise because find themselves core problems and find the correct development direction is the basic condition of enterprise development. For example, shuanghui and spring are both sausage company, they are found in the process of competition by each other's different development and strategic direction. ChunDou chooses to reduce your sausage quality level to reduce the cost of the sausage. Reducing the retail price of the sausage. So take advantage of the price. Instead, shuanghui company choose to develop their own quality of the sausage, to win the advantage of the quality of the sausage. Thus, the decision of the outcome is, ChunDou strategic choice is wrong, and shuanghui is right. In the end, shuanghui company victory. And because of the right strategy, shuanghui sausages to become popular.

In conclusion, I believe that cooperation and competition are favorable for the development of the company, only depends on different situation, should choose a different way.

\section{CONCLUSION}

The competition is between individuals or groups to trump or overwhelm the other side of the psychological needs and activities. It's being can make the enterprise spirits, strenuous enterprising, promote social progress and improve labor productivity. The disadvantages of it lie in its negative effect is to discourage both sides, make limited resources is difficult to play the best benefit, cause disunity between individuals or groups, is not conducive to the establishment and development of the interpersonal relationship.

Because one party is successful, means that the other party will fail.

Cooperation is a form of joint action, it is helpful to improve performance. For the two sides complement each other and mutual assistance. The disadvantages of cooperation are that may not be able to maximize its own interests. Cooperation and a drawback are that possible cooperation internal conflict. The conflict could lead to more conducive to both sides of the results.

This paper is just based on the surface of the talk about competition and cooperation of the two relations and advantages and disadvantages brought by the competition and cooperation relationship. No more depth to understand the pros and cons of competition and cooperation of the source and in the face of the rise of peer enterprises, the relationship between competition and cooperation between the two companies, which one is more conducive to choose. These two kinds of relationships in different companies and markets under the background of how to choose. Another problem is, whether competition and cooperation can exist at the same time. How to through the competition and cooperation to maximize their own interests. I think these problems are very interesting, are also very important. I will in the future study and investigate these aspects.

\section{ACKNOWLEDGMENT}

In the end part of the thesis, first I want to thank my professor. His classes are very interesting, because his class for trust games such as the interpretation of the game, let I have wanted to understand cooperation and competition between the enterprises want to party. And I would like to know how cooperation and competition among enterprises have advantages and disadvantages. Secondly, I would like to thank my assistant teacher and my thesis advisory teacher. My assistant teacher gave me a lot of help. During the professor in class, I have not 
understood the knowledge, is the assistant teacher to my patience. In terms of writing a paper, she has to give me useful hints and advice. And my thesis advisory teacher also gave me a lot of help. Because this is my first time to write a paper, contact me for the paper is to know nothing about this. The paper consulting teacher took a long time with me on the structure of the paper and should write content. It is very useful to me. And I want to thank my academic teacher because in the first preparation course, I am very confused. So, I thank her very much.

\section{REFERENCES}

[1] W. Qian, The cooperation and competition among enterprises,

https://wenku.baidu.com/view/04520766250c844769 eae009581b6bd97f19bcbc.html?fr=search-1-income1 -score_1-psrec2\&fixfr=a\%2FfJqoRx228sQf6VGzkL FQ\%3D\%3D, 2020.

[2] Sun Jipeng. The Cooperative Competition and Risk of Modern Enterprises[D]. Liaoning Technical University, 2002.

[3] Tan Manyan. Philosophical thinking on the relationship between competition and cooperation[J]. Guangdong Social Sciences, 2000(04): 71-75.

[4] Wan Yinghong, Li Jiang. Analysis on the Motivation of Enterprise Cooperation Strategy $[\mathrm{J}]$. China Soft Science, 2000(04):83-87.

[5] Z. Li, 2020, Cases of win-win cooperation between enterprises, https://wenku.baidu.com/view/339a603b4973f24233 6c1eb91a37f111f1850dab.html?fr=search-1-income 7 -score_1-psrec2\&fixfr=uTjWcc5f3MWuXZS2j9PJE w\%3D $\% 3 \mathrm{D}$

[6] Strategic Alliance Structuring: A Game Theoretic and Transaction Cost Examination of Cooperation. Parkhe A. The Academy of Management Journal. 1993 